\title{
Epiphyseal Union at the Innominate and Lower Limb in a Modern Portuguese Skeletal Sample, and Age Estimation in Adolescent and Young Adult Male and Female Skeletons
}

\author{
Hugo F.V. Cardoso* \\ Departamento de Antropologia, Universidade de Coimbra, Rua do Arco da Traição, 3000-056 Coimbra, Portugal \\ KEY WORDS skeletal age; bone maturation; socioeconomic status; Lisbon collection
}

\begin{abstract}
This study documents the timing of epiphyseal union at the innominate, femur, tibia, and fibula in a sample of modern Portuguese skeletons. The sample was taken from the Lisbon documented skeletal collection and it is comprised of 57 females and 49 males between the ages of 9 and 25. Individuals are mostly representative of the middle-to-low socioeconomic segment of the early 20th century Lisbon population. A total of 18 anatomical locations were examined for epiphyseal union using a three-stage scheme: 1) no union; 2) partial union; and 3) completed union, all traces of fusion having disappeared. Results show that females are ahead of males by 1-2 years and provide similar age ranges for the stages of union than previous studies. Some variations between studies can be explained by
\end{abstract}

methodological differences between dry bone and radiographic observations. However, a review of the literature indicates that socioeconomic status of a given population seems to be of decisive importance to the rate of ossification and most of the differences in skeletal maturation across studies and populations can probably be ascribed to different levels of social and economic development of the societies in which the individuals lived. Although the effects of socioeconomic status in skeletal maturation are greater during childhood than in adolescence, as to make the timing of epiphyseal union a reliable estimate of age at death, they are not negligible and age estimates should take into account the likely socioeconomic status of the individual, whose remains are under examination. Am J Phys Anthropol 135:161-170, 2008. @2007 Wiley-Liss, Inc.
The determination of age at the time of death is paramount in anthropological assessments of skeletal remains. This is true for bioarchaeological studies, where it is essential for the reconstruction of health and disease patterns or demography of past societies, or in forensic investigations, where it is critical for the positive identification of unidentified skeletal remains. Among the adolescent and young adult remains the timing of cessation of growth of the major bones of the skeleton is a common and one of the best age indicators (Ubelaker, 1987, 2005). The union of the various epiphyses occurs at a definite order and period of time in life and the correlation between age and timing of epiphyseal union can be used to establish an age at death. One additional value of epiphyseal union for age estimation is that all epiphyses do not all fuse simultaneously but vary from location to location, thus providing an ample range to which age can be estimated.

Several charts, compilations, and schemes have described the chronology of epiphyseal union in humans (Hodges, 1933; Greulich and Pyle, 1950; Acheson, 1954; Pyle and Hoerr, 1955; Hoerr et al., 1962; Ferembach et al., 1980; Tanner et al., 1983; Scheuer and Black, 2000). However, the purpose of the majority of these studies was to obtain population norms or average ages of skeletal maturation for clinical evaluations, and not intended to examine the full range of variation in skeletal maturity that can be found for each chronological age. Given that different individuals mature at different rates it is inappropriate to ascribe the normative age to an individual based on clinical evaluations. Instead, it is essential to establish an age range for probable age at death and precise data are needed to establish the narrowest ranges possible of skeletal ages for each chronological age. Another problem with most of the standards of skeletal maturation is that they are based on radiographic studies of living individuals, which are not necessarily duplicated by direct dry bone observations. Differences between radiographic and dry bone observations are related to problems of clarity of radiographs, training and experience in radiographic interpretation and recognition of stages of union (Krogman and Iscan, 1986). In addition, definitions of radiographic union of epiphyses may differ from those describing bones lacking soft tissue.

The major problem with chronologies based on dry bone observations is that rarely are large samples of documented skeletal remains available for examination

\footnotetext{
Grant sponsor: Fundação para a Ciência e Tecnologia, Portugal; Grant numbers: SFRH/BD/4917/2001 and SFRH/BPD/22142/2005.

*Correspondence to: Hugo F.V. Cardoso, Departamento de Antropologia, Universidade de Coimbra, Rua do Arco da Traição, 3000056 Coimbra, Portugal. E-mail: hcardoso@antrop.uc.pt
}

Received 17 May 2007; accepted 9 August 2007

DOI 10.1002/ajpa.20717

Published online 28 November 2007 in Wiley InterScience (www.interscience.wiley.com). 
(Stevenson, 1924; McKern and Stewart, 1957; Webb and Suchey, 1985; Albert and Maples, 1995). In addition, most documented skeletal series derive from western countries and may be unsuitable sources to evaluate contemporary populations because they consist mostly of individuals born from the early 1800 s to the early 1900 s. These countries have experienced major improvements in social and economic conditions, nutrition and medical care in the last few decades that are the basis for the documented secular trends in increasing height, weight, and accelerated maturation. For example, Himes (1984) documents a secular increase in the rates of hand-wrist ossification in British children during the 20th century. However, studies that are aimed at documenting the range of variation in skeletal maturity are frequently concerned in sampling groups of different ancestry or ethnicity (Webb and Suchey, 1985; Pfau and Sciulli, 1994; Crowder and Austin, 2005) (assuming that they reflect real population differences in genetic expression of ossification), and less attention has been paid to sampling or comparing groups of different socioeconomic condition. Schmeling et al. $(2000,2006)$ review the evidence of geographic, ethnic, or population differences in skeletal maturation and conclude that it is the socioeconomic status of a given population that is of decisive importance to the rate of ossification and that skeletal age is unaffected by ethnic identity or geneto-geographic origin. A relatively high level of economic progress and modernization in medicine coincides with accelerated ossification rates of the hand and wrist, whereas relatively low modernization seems to delay ossification (Schmeling et al., 2006). Seventy years ago Todd (1931) had already established no "race"-related differences in skeletal maturation, while stating that variability in the pattern and rate of ossification results mostly from illhealth, poor nutrition, or unhygienic conditions.

Although the rate of ossification is primarily affected by the socioeconomic development of the population concerned, skeletal maturation is differently affected by nutrition over the growth period, early childhood being more affected than adolescence. In a group of malnourished populations from Central America, Frisancho et al. $(1970 \mathrm{a}, \mathrm{b})$ found that skeletal maturation in poor adolescents was only 5-9\% delayed relative to US standards, compared with a delay of $36-38 \%$ in early childhood. Similar results have also been reported by Dreizen et al. (1967) and Pickett et al. (1995) for US and Guatemalan malnourished children, respectively. These findings suggest that socioeconomic status and secular trend effects within the same population and different levels of social and economic development between populations have a small, but still significant effect in timing of epiphyseal union. This may explain why Crowder and Austin (2005) report advanced ages of union of contemporary North American adolescents compared with earlier studies and why Indian youths (Banerjee and Agarwal, 1998) seem around 1 year delayed in epiphyseal union compared to North American teenagers (Crowder and Austin, 2005), although earliest and latest ages of union are similar in both studies.

This study is an attempt to document the timing of epiphyseal union at the innominate and lower limb in a sample of modern Portuguese male and female skeletons from the early 20th century. Although the adolescents and young adults in the study sample do not represent either the well off or the extremely disadvantaged segments of the early 20th Portuguese society, they may serve as a reference sample for many populations experiencing lower levels of social and economic development. This may include prehistoric or historic populations studied by bioarchaeologists or people from developing countries investigated by forensic anthropologists. Because dry bone data are very scarce, particularly for females, and because there is very few information for some anatomical locations, such as the femoral head, which cannot be adequately assessed for in radiographs, this study is an attempt to fill in those gaps by providing a comprehensive record of timing of epiphyseal union and contributing to a more complete understanding of its population variability.

\section{MATERIAL AND METHODS}

The sample used in this study consists of the skeletal remains of 106 individuals of known sex and age at death from the Lisbon documented skeletal collection (Cardoso, 2006). The sample derives from modern cemetery sources and comprises individuals buried between 1903 and 1975. The majority died between 1930 and 1960. Years of birth range from 1887 to 1960 , with the majority of birth dates falling between 1910 and 1930 . The remains represent the middle-to-low social class of the city of Lisbon, as inferred from the origin of the remains (temporary graves) (Cardoso, 2006). The occupations of the adult male segment of the collection, as well as the occupations of the fathers of the nonadult segment, include a large proportion of menial jobs and, thus, are also suggestive of a lower socioeconomic status for the collection (Cardoso, 2005, 2007). In other skeletal reference collections, such as the Terry Collection (curated at the Smithsonian Institution's National Museum of Natural History in Washington, D.C.), cadavers not claimed by their relatives at local morgues were made available to the medical school for anatomy classes and these make up the majority of skeletons (Hunt and Albanese, 2005). These cadavers represent a very low stratum of society that is completely absent from the Lisbon Collection. However, it may be misleading to assume that the Terry collection is of lower socioeconomic status because while in the individuals of the Terry collection poverty may have been acute or lasted as little as a few years before death (Albanese, 2003), in the individuals of the Lisbon collection poverty was chronic throughout the lifetime and spanned several generations (see Cardoso, 2007, for a more detailed description of the socioeconomic background of the study sample).

Chronological ages were obtained from death civil records. Although dates of birth are known for most individuals under 20 years, as to provide exact calendar ages in months or days, individuals were assigned to 1year age intervals. Given that some concerns are frequently raised regarding the accuracy of age at death in documented skeletal collections (Webb and Suchey, 1985), it was necessary to validate such information. Cross-verifying the reported age in the death record with the difference between dates of birth and death showed no major discrepancies in the age of the nonadult ( $<20$ years) segment of the collection (Cardoso, 2007). This also suggests accurate ages at death in the young adult segment of the collection, particularly at the 1-year interval accuracy level. Ages in the sample range from 9 to 25 years and there is a slight over-representa- 


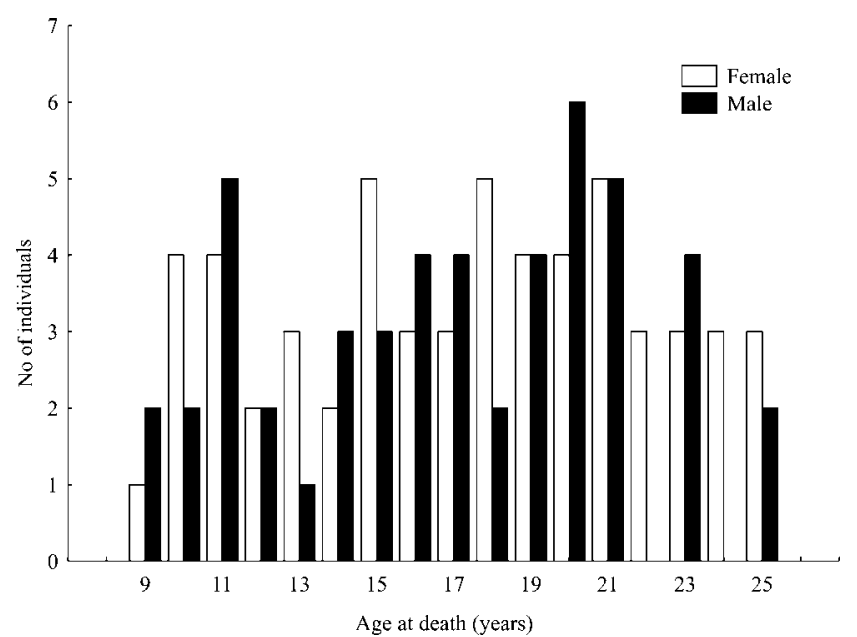

Fig. 1. Age and sex distribution of the study sample (females, 57; males, 49).

tion of female skeletons (females, 57; males, 49). Upper and lower age limits were established during the data collection process according to observations of epiphyseal union. The age and sex distribution of the sample is depicted in Figure 1. Only males at the ages of 22 and 24 are not represented.

Epiphyseal union was recorded at the femur, tibia, fibula, and innominate using a three-stage scale according to Johnston (1961): 1) no union; 2) partial union; and 3) completed union, all traces of fusion having disappeared (Fig. 2). When the epiphysis is completely fused and no gaps are visible, the epiphyseal-diaphyseal junction may show an epiphyseal line or scar, which should not be mistaken for partial union (the location is scored as completed union). A three-stage scale was preferred to reduce the imprecision of scoring in repeated observations, since successive stages defined by commencement of fusion and advanced fusion can be only marginally different. Four locations were examined in the femur: 1) proximal epiphysis; 2) greater trochanter; 3) lesser trochanter; and 4) distal epiphysis. Two locations were observed in the tibia and fibula: 1) proximal epiphysis; and 2) distal epiphysis. In the innominate, 10 locations were examined according to the detailed descriptions of Scheuer and Black (2000), for the parts of the innominate undergoing fusion during adolescence and late adulthood. The following three locations are not considered epiphysis: 1) ilium-pubis union; 2) ilium-ischium union; and 3) ischium-pubis union. The epiphyses examined in the innominate are: 1) Os acetabuli; 2) posterior acetabular epiphysis; 3) superior acetabular epiphysis; 4) anterior superior iliac spine; 5) iliac crest; 6) ischial epiphysis; and 7) ramal epiphysis. Because development of the innominate is more complex than that of the long bones, particularly at the triradiate unit-acetabulum area, scoring of epiphyseal union of this part of the skeleton followed closely the description of these anatomical regions by Scheuer and Black (2000). Union of the ischiumilium-pubis was scored in relation to the three flanges, which are strips of epiphyseal cartilage that separate each of the three bony parts from its counterpart on the opposite side (Scheuer and Black, 2000). Long and multipartite epiphyses of the innominate, such as the iliac crest, were scored as partially united as long as only one

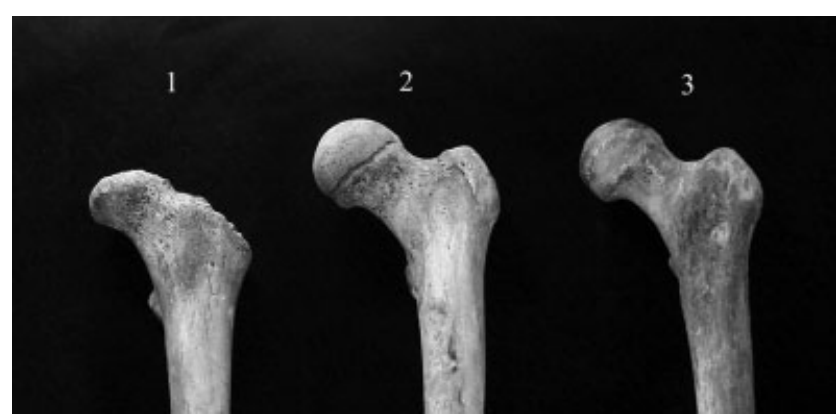

Fig. 2. Stages of union of the femoral proximal epiphysis, 1, nonunion; 2, partial union, and 3, completed union, all traces of fusion having disappeared.

element began union along its entire surface, and was only scored as completely fused when the whole epiphyseal strip showed no gaps with the iliac blade. Specimens were examined blind without prior knowledge of the sex and age. Scoring was targeted at left bones, but the right side was used if the left was unavailable. Because of preservation problems, some anatomical locations could not be observed in some specimens. This means that sample sizes vary according to epiphysealdiaphyseal location. No restorative work has been done on the specimens of the Lisbon collection and, therefore, there are no concerns regarding gluing of epiphysis (Coqueugniot and Weaver, 2007). Pathological specimens were also excluded from the analysis.

\section{RESULTS}

Table 1 shows a summary of age intervals for epiphyseal union at the innominate, femur, tibia, and fibula. Data are broken down by anatomical location and by sex. Ages are established at 1-year intervals and represent the interval between the value of one age and the next. The last three columns of Table 1 are identified with the headings Stage 1, Stage 2, and Stage 3. The first column (Stage 1) indicates the age of the oldest individual at Stage 1 (no union), that is, the age after which the anatomical location is either partially or completely fused. The second column (Stage 2) shows the age range of individuals at Stage 2 (partial union), that is, the youngest and oldest age at which the anatomical location is in the process of becoming fused. Finally, the third column (Stage 3) indicates the age of the youngest individual at Stage 3 (completed union), that is, the age before which the anatomical location is either unfused or only partially fused. The purpose of these three columns is to provide the researcher prompt information with which to assess the age of unidentified skeletal remains. If the specimen under examination shows partially united (Stage 2) epiphysis, Table 1 provides an estimated age interval for the specimen's true chronological age. Using the proximal femur as an example, if a certain unidentified specimen shows a partial union at this location, the estimated age interval is 14-18 years (14-16 years for females and 15-18 years for males). If the specimen shows an unfused or completely fused epiphysis, data in Table 1 will only provide an upper or lower limit for the estimated age interval, respectively. For example, 
TABLE 1. Summary of ages (in years) of epiphyseal union at the innominate, femur, tibia, and fibula

\begin{tabular}{|c|c|c|c|c|c|}
\hline Bone & Epiphysis & Sex & Stage 1 & Stage 2 & Stage 3 \\
\hline \multirow[t]{20}{*}{ Innominate } & \multirow[t]{2}{*}{ Acetabulum: ilium-pubis } & 우 & $\leq 14$ & $13(n=2)$ & $\geq 11$ \\
\hline & & to & $\leq 16$ & $14-15(n=2)$ & $\geq 15$ \\
\hline & \multirow[t]{2}{*}{ Acetabulum: ilium-ischium } & + & $\leq 14$ & $13(n=1)$ & $\geq 11$ \\
\hline & & $\hat{0}$ & $<16$ & $11-15(n=3)$ & $>15$ \\
\hline & \multirow[t]{2}{*}{ Acetabulum: ischium-pubis } & q & $\leq 14$ & $11-13(n=3)$ & $\geq 14$ \\
\hline & & $\hat{0}$ & $\leq 16$ & $15-18(n=4)$ & $\geq 15$ \\
\hline & \multirow[t]{2}{*}{ Os acetabuli } & q & $\leq 14$ & $11-16(n=4)$ & $\geq 14$ \\
\hline & & $\hat{0}$ & $\leq 16$ & $14-17(n=4)$ & $\geq 15$ \\
\hline & \multirow[t]{2}{*}{ Posterior acetabular epiphysis } & q & $\leq 14$ & $11-13(n=4)$ & $\geq 14$ \\
\hline & & $\hat{0}$ & $\leq 16$ & $11-17(n=4)$ & $\geq 15$ \\
\hline & \multirow[t]{2}{*}{ Superior acetabular epiphysis } & o & $\leq 14$ & $11-16(n=4)$ & $\geq 14$ \\
\hline & & $\hat{0}$ & $\leq 16$ & $11-17(n=6)$ & $\geq 15$ \\
\hline & \multirow[t]{2}{*}{ Anterior superior iliac spine } & q & $\leq 15$ & $15-16(n=3)$ & $\geq 14$ \\
\hline & & 0 & $\leq 15$ & $15(n=1)$ & $\geq 15$ \\
\hline & \multirow[t]{2}{*}{ Iliac crest } & o & $\leq 16$ & $15-21(n=17)$ & $\geq 18$ \\
\hline & & $\hat{0}$ & $\leq 14$ & $16-21(n=10)$ & $\geq 19$ \\
\hline & \multirow[t]{2}{*}{ Ischial epiphysis } & q & $\leq 15$ & $14-19(n=12)$ & $\geq 16$ \\
\hline & & $\hat{0}$ & $\leq 16$ & $15-21(n=7)$ & $\geq 17$ \\
\hline & \multirow[t]{2}{*}{ Ramal epiphysis } & o & $\leq 20$ & $18-22(n=7)$ & $\geq 18$ \\
\hline & & $\hat{0}$ & $\leq 21$ & $17-21(n=6)$ & $\geq 18$ \\
\hline \multirow{8}{*}{ Femur } & \multirow{2}{*}{ Proximal epiphysis } & 웅 & $<15$ & $14-16(n=6)$ & $>15$ \\
\hline & & $\hat{o}$ & $\leq 16$ & $15-18(n=4)$ & $\geq 16$ \\
\hline & \multirow[t]{2}{*}{ Greater trochanter } & q & $\leq 15$ & $13-16(n=5)$ & $\geq 14$ \\
\hline & & 0 & $\leq 16$ & $15-18(n=4)$ & $\geq 16$ \\
\hline & \multirow{2}{*}{ Lesser trochanter } & 우 & $<15$ & $13-16(n=6)$ & $>14$ \\
\hline & & $\hat{0}$ & $\leq 16$ & $15-18(n=4)$ & $\geq 16$ \\
\hline & \multirow[t]{2}{*}{ Distal epiphysis } & q & $\leq 16$ & $14-19(n=8)$ & $\geq 17$ \\
\hline & & $\hat{0}$ & $\leq 18$ & $17(n=1)$ & $\geq 16$ \\
\hline \multirow[t]{4}{*}{ Tibia } & \multirow[t]{2}{*}{ Proximal epiphysis } & 우 & $\leq 16$ & $14-19(n=13)$ & $\geq 18$ \\
\hline & & $0^{2}$ & $\leq 18$ & $16-19(n=7)$ & $\geq 17$ \\
\hline & \multirow[t]{2}{*}{ Distal epiphysis } & q & $\leq 16$ & $14-16(n=5)$ & $\geq 15$ \\
\hline & & $\hat{0}$ & $\leq 18$ & $15-17(n=4)$ & $\geq 16$ \\
\hline \multirow[t]{4}{*}{ Fibula } & \multirow[t]{2}{*}{ Proximal epiphysis } & 우 & $\leq 16$ & $14-17(n=5)$ & $\geq 17$ \\
\hline & & $0^{2}$ & $\leq 18$ & $17(n=1)$ & $\geq 16$ \\
\hline & \multirow{2}{*}{ Distal epiphysis } & q & $\leq 16$ & $14-16(n=3)$ & $\geq 15$ \\
\hline & & ô & $\leq 16$ & $15-18(n=6)$ & $\geq 17$ \\
\hline
\end{tabular}

Stage 1 column indicates the age of the oldest individual at Stage 1; Stage 2 column indicates the age interval for the youngest and oldest individuals at Stage 2; and Stage 3 column indicates the age of the youngest individuals at Stage 3.

TABLE 2. Age distribution of stages of the ilium-pubis union (\%)

\begin{tabular}{|c|c|c|c|c|c|c|c|c|}
\hline \multirow[b]{2}{*}{ Age } & \multirow[b]{2}{*}{$N$} & \multicolumn{3}{|c|}{$\begin{array}{c}\text { Females } \\
\text { (stage of union) }\end{array}$} & \multirow[b]{2}{*}{$N$} & \multicolumn{3}{|c|}{$\begin{array}{c}\text { Males } \\
\text { (stage of union) }\end{array}$} \\
\hline & & 1 & 2 & 3 & & 1 & 2 & 3 \\
\hline 9 & 2 & 100 & - & - & 2 & 100 & - & - \\
\hline 10 & 4 & 100 & - & - & 2 & 100 & - & - \\
\hline 11 & 4 & 75 & - & 25 & 5 & 100 & - & - \\
\hline 12 & 2 & 100 & - & - & 2 & 100 & - & - \\
\hline 13 & 2 & - & 100 & - & 1 & 100 & - & - \\
\hline 14 & 2 & 50 & - & 50 & 3 & 66 & 33 & - \\
\hline 15 & 5 & - & - & 100 & 3 & - & 33 & 66 \\
\hline 16 & 3 & - & - & 100 & 4 & 25 & - & 75 \\
\hline 17 & 2 & - & - & 100 & 4 & - & - & 100 \\
\hline 18 & 4 & - & - & 100 & 2 & - & - & 100 \\
\hline
\end{tabular}

if the iliac crest is not fused, the specimen is likely to be under 18 years of age. If independent information regarding the sex of the individual can be obtained, such as from clothes in forensic cases, the appropriate male or female age ranges can be assigned. More detailed information about ages of union in all 18 anatomical locations is shown in Tables $2-19$. Tables $2-11$ show the age distributions for each stage of union in the 10 anatomical locations of the innominate. Tables 12-15 show the age distributions for each stage of union in the four anatomical locations of the femur. Tables 16 and 17 show the age
TABLE 3. Age distribution of stages of ilium-ischium union (\%)

\begin{tabular}{|c|c|c|c|c|c|c|c|c|}
\hline \multirow[b]{2}{*}{ Age } & \multirow[b]{2}{*}{$N$} & \multicolumn{3}{|c|}{$\begin{array}{c}\text { Females } \\
\text { (stage of union) }\end{array}$} & \multirow[b]{2}{*}{$N$} & \multicolumn{3}{|c|}{$\begin{array}{c}\text { Males } \\
\text { (stage of union) }\end{array}$} \\
\hline & & 1 & 2 & 3 & & 1 & 2 & 3 \\
\hline 9 & 2 & 100 & - & - & 2 & 100 & - & - \\
\hline 10 & 4 & 100 & - & - & 2 & 100 & - & - \\
\hline 11 & 4 & 75 & - & 25 & 5 & 80 & 20 & - \\
\hline 12 & 2 & 100 & - & - & 2 & 100 & - & - \\
\hline 13 & 3 & - & 33 & 66 & 1 & 100 & - & - \\
\hline 14 & 2 & 50 & - & 50 & 3 & 66 & 33 & - \\
\hline 15 & 5 & - & - & 100 & 3 & - & 33 & 66 \\
\hline 16 & 3 & - & - & 100 & 4 & 25 & - & 75 \\
\hline 17 & 2 & - & - & 100 & 4 & - & - & 100 \\
\hline 18 & 4 & - & - & 100 & 2 & - & - & 100 \\
\hline
\end{tabular}

distributions for each stage of union in the two epiphysis of the tibia. Finally, the age distributions for each stage of union in the two epiphyses of the fibula are shown in Tables 18 and 19.

Sample sizes are small but results show a rather even and consistent distribution of individuals in all stages for most epiphyseal-diaphyseal locations. Some locations, however, show more erratic distributions and very few individuals at key ages around the age of partial union. For example, ages of partial union of the iliumischium at the acetabulum for females, the superior 
TABLE 4. Age distribution of stages of ischium-pubis union (\%)

\begin{tabular}{|c|c|c|c|c|c|c|c|c|}
\hline \multirow[b]{2}{*}{ Age } & \multirow[b]{2}{*}{$N$} & \multicolumn{3}{|c|}{$\begin{array}{c}\text { Females } \\
\text { (stage of union) }\end{array}$} & \multirow[b]{2}{*}{$N$} & \multicolumn{3}{|c|}{$\begin{array}{c}\text { Males } \\
\text { (stage of union) }\end{array}$} \\
\hline & & 1 & 2 & 3 & & 1 & 2 & 3 \\
\hline 9 & 2 & 100 & - & - & 2 & 100 & - & - \\
\hline 10 & 4 & 100 & - & - & 2 & 100 & - & - \\
\hline 11 & 4 & 75 & 25 & - & 5 & 100 & - & - \\
\hline 12 & 2 & 100 & - & - & 2 & 100 & - & - \\
\hline 13 & 2 & - & 100 & - & 1 & 100 & - & - \\
\hline 14 & 2 & 50 & - & 50 & 3 & 100 & - & - \\
\hline 15 & 4 & - & - & 100 & 3 & - & 66 & 33 \\
\hline 16 & 3 & - & - & 100 & 4 & 25 & - & 75 \\
\hline 17 & 3 & - & - & 100 & 4 & - & 25 & 75 \\
\hline 18 & 5 & - & - & 100 & 2 & - & 50 & 50 \\
\hline 19 & 4 & - & - & 100 & 3 & - & - & 100 \\
\hline 20 & 4 & - & - & 100 & 2 & - & - & 100 \\
\hline
\end{tabular}

TABLE 7. Age distribution of stages of union of the superior acetabular epiphysis (\%)

\begin{tabular}{|c|c|c|c|c|c|c|c|c|}
\hline \multirow[b]{2}{*}{ Age } & \multirow[b]{2}{*}{$N$} & \multicolumn{3}{|c|}{$\begin{array}{c}\text { Females } \\
\text { (stage of union) }\end{array}$} & \multirow[b]{2}{*}{$N$} & \multicolumn{3}{|c|}{$\begin{array}{c}\text { Males } \\
\text { (stage of union) }\end{array}$} \\
\hline & & 1 & 2 & 3 & & 1 & 2 & 3 \\
\hline 9 & 2 & 100 & - & - & 2 & 100 & - & - \\
\hline 10 & 4 & 100 & - & - & 2 & 100 & - & - \\
\hline 11 & 4 & 75 & 25 & - & 5 & 80 & 20 & - \\
\hline 12 & 2 & 100 & - & - & 2 & 100 & - & - \\
\hline 13 & 3 & 33 & 66 & - & 1 & 100 & - & - \\
\hline 14 & 2 & 50 & - & 50 & 3 & 66 & 33 & - \\
\hline 15 & 5 & - & - & 100 & 3 & - & 33 & 66 \\
\hline 16 & 3 & - & 33 & 66 & 4 & 25 & 50 & 25 \\
\hline 17 & 3 & - & - & 100 & 4 & - & 25 & 75 \\
\hline 18 & 5 & - & - & 100 & 2 & - & - & 100 \\
\hline 19 & 3 & - & - & 100 & 4 & - & - & 100 \\
\hline
\end{tabular}

TABLE 5. Age distribution of stages of union of the Os acetabuli (\%)

\begin{tabular}{lcccccccc}
\hline & \multicolumn{4}{c}{$\begin{array}{c}\text { Females } \\
\text { Agtage of union) }\end{array}$} & & \multicolumn{3}{c}{$\begin{array}{c}\text { Males } \\
\text { (stage of union) }\end{array}$} \\
\cline { 3 - 5 } \cline { 7 - 9 } & $N$ & 1 & 2 & 3 & $N$ & 1 & 2 & 3 \\
\hline 9 & 2 & 100 & - & - & 2 & 100 & - & - \\
10 & 4 & 100 & - & - & 2 & 100 & - & - \\
11 & 4 & 75 & 25 & - & 5 & 100 & - & - \\
12 & 2 & 100 & - & - & 2 & 100 & - & - \\
13 & 2 & - & 100 & - & 1 & 100 & - & - \\
14 & 2 & 50 & - & 50 & 3 & 66 & 33 & - \\
15 & 5 & - & - & 100 & 3 & - & 33 & 66 \\
16 & 3 & - & 33 & 66 & 4 & 25 & 25 & 50 \\
17 & 3 & - & - & 100 & 4 & - & 25 & 75 \\
18 & 5 & - & - & 100 & 2 & - & - & 100 \\
19 & 4 & - & - & 100 & 4 & - & - & 100 \\
\hline
\end{tabular}

TABLE 6. Age distribution of stages of union of the posterior acetabular epiphysis (\%)

\begin{tabular}{lcccccccc}
\hline & \multicolumn{4}{c}{$\begin{array}{c}\text { Females } \\
\text { (stage of union) }\end{array}$} & & \multicolumn{3}{c}{$\begin{array}{c}\text { Males } \\
\text { (stage of union) }\end{array}$} \\
\cline { 3 - 5 } \cline { 7 - 9 } Age & $N$ & 1 & 2 & 3 & & 1 & 2 & 3 \\
\hline 9 & 2 & 100 & - & - & 2 & 100 & - & - \\
10 & 4 & 100 & - & - & 2 & 100 & - & - \\
11 & 4 & 75 & 25 & - & 5 & 80 & 20 & - \\
12 & 2 & 100 & - & - & 2 & 100 & - & - \\
13 & 3 & - & 100 & - & 1 & 100 & - & - \\
14 & 2 & 50 & - & 50 & 3 & 66 & 33 & - \\
15 & 4 & - & - & 100 & 3 & - & 33 & 66 \\
16 & 3 & - & - & 100 & 4 & 25 & - & 75 \\
17 & 3 & - & - & 100 & 4 & - & 25 & 75 \\
18 & 5 & - & - & 100 & 2 & - & - & 100 \\
19 & 4 & - & - & 100 & 4 & - & - & 100 \\
\hline
\end{tabular}

anterior iliac spine for males, the distal femur for males and the proximal fibula also for males, are based only in one individual. Most age intervals at Stage 2 are comprised of more than four observations, but some have considerably more. This is the case of the iliac crest for females $(n=17)$ and males $(n=10)$ or the ischial epiphysis $(n=12)$ and proximal tibia $(n=13)$ also for females. Given that data obtained in this study are cross-sectional, age variability in stages of union increases and the probability of observing the actual union of epiphysis tends to diminish, as the chance that the time of death coincides with the actual moment of
TABLE 8. Age distribution of stages of union of the anterior superior iliac spine (\%)

\begin{tabular}{|c|c|c|c|c|c|c|c|c|}
\hline \multirow[b]{2}{*}{ Age } & \multirow[b]{2}{*}{$N$} & \multicolumn{3}{|c|}{$\begin{array}{c}\text { Females } \\
\text { (stage of union) }\end{array}$} & \multirow[b]{2}{*}{$N$} & \multicolumn{3}{|c|}{$\begin{array}{c}\text { Males } \\
\text { (stage of union) }\end{array}$} \\
\hline & & 1 & 2 & 3 & & 1 & 2 & 3 \\
\hline 11 & 4 & 100 & - & - & 5 & 100 & - & - \\
\hline 12 & 2 & 100 & - & - & 2 & 100 & - & - \\
\hline 13 & 3 & 100 & - & - & 1 & 100 & - & - \\
\hline 14 & 2 & 50 & - & 50 & 3 & 100 & - & - \\
\hline 15 & 5 & 20 & 20 & 60 & 3 & 33 & 33 & 33 \\
\hline 16 & 3 & - & 66 & 33 & 3 & - & - & 100 \\
\hline 17 & 3 & - & - & 100 & 4 & - & - & 100 \\
\hline 18 & 5 & - & - & 100 & 2 & - & - & 100 \\
\hline 19 & 3 & - & - & 100 & 4 & - & - & 100 \\
\hline
\end{tabular}

TABLE 9. Age distribution of stages of union of the iliac crest (\%)

\begin{tabular}{|c|c|c|c|c|c|c|c|c|}
\hline \multirow[b]{2}{*}{ Age } & \multirow[b]{2}{*}{$N$} & \multicolumn{3}{|c|}{$\begin{array}{c}\text { Females } \\
\text { (stage of union) }\end{array}$} & \multirow[b]{2}{*}{$N$} & \multicolumn{3}{|c|}{$\begin{array}{c}\text { Males } \\
\text { (stage of union) }\end{array}$} \\
\hline & & 1 & 2 & 3 & & 1 & 2 & 3 \\
\hline 13 & 3 & 100 & - & - & 1 & 100 & - & _ \\
\hline 14 & 2 & 100 & - & - & 3 & 100 & - & - \\
\hline 15 & 5 & 80 & 20 & - & 3 & 100 & - & - \\
\hline 16 & 3 & 100 & - & - & 3 & 66 & 33 & - \\
\hline 17 & 3 & - & 100 & - & 4 & 25 & 75 & - \\
\hline 18 & 5 & - & 40 & 60 & 2 & 50 & 50 & - \\
\hline 19 & 3 & - & 100 & - & 4 & - & 50 & 50 \\
\hline 20 & 4 & - & 75 & 25 & 5 & - & 40 & 60 \\
\hline 21 & 5 & - & 100 & - & 4 & - & 25 & 75 \\
\hline 22 & 3 & - & - & 100 & - & - & - & - \\
\hline 23 & 3 & - & - & 100 & 4 & & - & 100 \\
\hline
\end{tabular}

union is small. The smaller the period of time for the epiphyseal-diaphyseal union to take place the smaller is the chance that an individual, who dies at a particular age, coincides with the actual moment of union.

In the innominate, union at the ilium-ischium-pubis and acetabulum starts at around 11 years of age, slightly later for males at some locations. By age 15, most of the growth at these locations seems to cease. Comparatively, the iliac spine, iliac crest, and ischial and ramal epiphyses fuse later. This starts to occur at around 15 years of age and later, with males showing a slight delay, relative to females, except for the ramal epiphysis. At age 21-22, 
TABLE 10. Age distribution of stages of union of the ischial epiphysis (\%)

\begin{tabular}{|c|c|c|c|c|c|c|c|c|}
\hline \multirow[b]{2}{*}{ Age } & \multirow[b]{2}{*}{$N$} & \multicolumn{3}{|c|}{$\begin{array}{c}\text { Females } \\
\text { (stage of union) }\end{array}$} & \multirow[b]{2}{*}{$N$} & \multicolumn{3}{|c|}{$\begin{array}{c}\text { Males } \\
\text { (stage of union) }\end{array}$} \\
\hline & & 1 & 2 & 3 & & 1 & 2 & 3 \\
\hline 12 & 2 & 100 & - & - & 1 & 100 & - & - \\
\hline 13 & 3 & 100 & - & - & 1 & 100 & - & - \\
\hline 14 & 2 & 50 & 50 & - & 3 & 100 & - & - \\
\hline 15 & 5 & 20 & 80 & - & 3 & 66 & 33 & - \\
\hline 16 & 3 & - & 66 & 33 & 3 & 66 & 33 & - \\
\hline 17 & 3 & - & 66 & 33 & 4 & - & 50 & \\
\hline 18 & 5 & - & 20 & 80 & 1 & - & 100 & - \\
\hline 19 & 3 & - & 66 & 33 & 4 & - & 25 & \\
\hline 20 & 4 & - & - & 100 & 5 & - & - & \\
\hline 21 & 5 & - & - & 100 & 4 & - & 25 & \\
\hline 22 & 3 & - & - & 100 & 3 & - & - & \\
\hline 23 & 3 & - & - & 100 & 4 & - & - & \\
\hline
\end{tabular}

TABLE 11. Age distribution of stages of union of the ramal epiphysis (\%)

\begin{tabular}{lccccccccc}
\hline & \multicolumn{1}{c}{$\begin{array}{c}\text { Females } \\
\text { Age }\end{array}$} & $N$ & & 1 & 2 & 3 & & \multicolumn{3}{c}{$\begin{array}{c}\text { Males } \\
\text { (stage of union) }\end{array}$} & & & 1 & 2 & 3 \\
\hline 15 & 5 & 100 & - & - & 3 & 100 & - & - \\
16 & 3 & 100 & - & - & 3 & 100 & - & - \\
17 & 3 & 100 & - & - & 4 & 50 & 50 & - \\
18 & 5 & 60 & 20 & 20 & 2 & 50 & - & 50 \\
19 & 3 & 33 & 33 & 33 & 3 & 33 & 66 & - \\
20 & 4 & 75 & - & 25 & 5 & 20 & 20 & 60 \\
21 & 4 & - & 100 & - & 4 & 25 & 25 & 50 \\
22 & 3 & - & 33 & 66 & - & - & - & - \\
23 & 3 & - & - & 100 & 4 & - & - & 100 \\
24 & 3 & - & - & 100 & - & - & - & - \\
\hline
\end{tabular}

TABLE 12. Age distribution of stages of union of the proximal femur (\%)

\begin{tabular}{|c|c|c|c|c|c|c|c|c|}
\hline \multirow[b]{2}{*}{ Age } & \multirow[b]{2}{*}{$N$} & \multicolumn{3}{|c|}{$\begin{array}{c}\text { Females } \\
\text { (stage of union) }\end{array}$} & \multirow[b]{2}{*}{$N$} & \multicolumn{3}{|c|}{$\begin{array}{c}\text { Males } \\
\text { (stage of union) }\end{array}$} \\
\hline & & 1 & 2 & 3 & & 1 & 2 & 3 \\
\hline 12 & 2 & 100 & - & - & 2 & 100 & - & - \\
\hline 13 & 3 & 100 & - & - & 1 & 100 & - & - \\
\hline 14 & 2 & 50 & 50 & - & 3 & 100 & - & - \\
\hline 15 & 5 & 20 & 60 & 20 & 3 & 66 & 33 & - \\
\hline 16 & 3 & - & 66 & 33 & 4 & 50 & 25 & 25 \\
\hline 17 & 3 & - & - & 100 & 4 & - & 25 & 75 \\
\hline 18 & 5 & - & - & 100 & 2 & - & 50 & 50 \\
\hline 19 & 4 & - & - & 100 & 4 & - & - & 100 \\
\hline 20 & 4 & - & - & 100 & 6 & - & - & 100 \\
\hline
\end{tabular}

the hipbone completes its growth and attains adult size and shape. In the lower limb, all the long bones show a similar pattern. Epiphyses fuse between around 14-16 years in females and 15-18 years in males, with the epiphyses at the knee showing a slightly later age of union. By age 19 the femur, tibia, and fibula attain the adult size and shape. Overall, males are around 1-2 years behind females, except for some epiphyseal-diaphyseal locations where there is either considerable overlap between the sexes or small sample sizes do not provide sufficient observations.
TABLE 13. Age distribution of stages of union of the greater trochanter of the femur (\%)

\begin{tabular}{|c|c|c|c|c|c|c|c|c|}
\hline \multirow[b]{2}{*}{ Age } & \multirow[b]{2}{*}{$N$} & \multicolumn{3}{|c|}{$\begin{array}{c}\text { Females } \\
\text { (stage of union) }\end{array}$} & \multirow[b]{2}{*}{$N$} & \multicolumn{3}{|c|}{$\begin{array}{c}\text { Males } \\
\text { (stage of union) }\end{array}$} \\
\hline & & 1 & 2 & 3 & & 1 & 2 & 3 \\
\hline 11 & 4 & 100 & - & - & 5 & 100 & - & - \\
\hline 12 & 2 & 100 & - & - & 2 & 100 & - & - \\
\hline 13 & 3 & 66 & 33 & - & 1 & 100 & - & - \\
\hline 14 & 2 & 50 & - & 50 & 3 & 100 & - & - \\
\hline 15 & 5 & 20 & 40 & 40 & 3 & 66 & 33 & - \\
\hline 16 & 3 & - & 66 & 33 & 4 & 50 & 25 & 25 \\
\hline 17 & 3 & - & - & 100 & 4 & - & 25 & 75 \\
\hline 18 & 5 & - & - & 100 & 2 & - & 50 & 50 \\
\hline 19 & 4 & - & - & 100 & 4 & - & - & 100 \\
\hline 20 & 4 & - & - & 100 & 6 & - & - & 100 \\
\hline
\end{tabular}

TABLE 14. Age distribution of stages of union of the lesser trochanter of the femur (\%)

\begin{tabular}{|c|c|c|c|c|c|c|c|c|}
\hline \multirow[b]{2}{*}{ Age } & \multirow[b]{2}{*}{$N$} & \multicolumn{3}{|c|}{$\begin{array}{c}\text { Females } \\
\text { (stage of union) }\end{array}$} & \multirow[b]{2}{*}{$N$} & \multicolumn{3}{|c|}{$\begin{array}{c}\text { Males } \\
\text { (stage of union) }\end{array}$} \\
\hline & & 1 & 2 & 3 & & 1 & 2 & 3 \\
\hline 11 & 3 & 100 & - & - & 5 & 100 & - & - \\
\hline 12 & 2 & 100 & - & - & 2 & 100 & - & - \\
\hline 13 & 3 & 66 & 33 & - & 1 & 100 & - & - \\
\hline 14 & 2 & 50 & - & 50 & 3 & 100 & - & - \\
\hline 15 & 5 & 20 & 60 & 20 & 3 & 66 & 33 & - \\
\hline 16 & 3 & - & 66 & 33 & 4 & 50 & 25 & 25 \\
\hline 17 & 2 & - & - & 100 & 4 & - & 25 & 75 \\
\hline 18 & 4 & - & - & 100 & 2 & - & 50 & 50 \\
\hline 19 & 3 & - & - & 100 & 4 & - & - & 100 \\
\hline 20 & 4 & - & - & 100 & 6 & - & - & 100 \\
\hline
\end{tabular}

TABLE 15. Age distribution of stages of union of the distal femur (\%)

\begin{tabular}{|c|c|c|c|c|c|c|c|c|}
\hline \multirow[b]{2}{*}{ Age } & \multirow[b]{2}{*}{$N$} & \multicolumn{3}{|c|}{$\begin{array}{c}\text { Females } \\
\text { (stage of union) }\end{array}$} & \multirow[b]{2}{*}{$N$} & \multicolumn{3}{|c|}{$\begin{array}{c}\text { Males } \\
\text { (stage of union) }\end{array}$} \\
\hline & & 1 & 2 & 3 & & 1 & 2 & 3 \\
\hline 12 & 2 & 100 & _ & - & 2 & 100 & - & - \\
\hline 13 & 3 & 100 & - & - & 1 & 100 & - & - \\
\hline 14 & 2 & 50 & 50 & - & 3 & 100 & - & - \\
\hline 15 & 5 & 60 & 40 & - & 3 & 100 & - & - \\
\hline 16 & 3 & 33 & 66 & - & 4 & 75 & - & 25 \\
\hline 17 & 3 & - & 33 & 66 & 4 & 25 & 25 & 50 \\
\hline 18 & 5 & - & 20 & 80 & 2 & 50 & - & 50 \\
\hline 19 & 4 & - & 25 & 75 & 4 & - & - & 100 \\
\hline 20 & 4 & - & - & 100 & 6 & - & - & 100 \\
\hline 21 & 5 & - & - & 100 & 5 & - & - & 100 \\
\hline
\end{tabular}

\section{DISCUSSION}

This study documents the timing of epiphyseal union at the innominate, femur, tibia, and fibula in a sample of modern Portuguese skeletons. There is scarce dry bone data for females and for some anatomical locations, and this study is an attempt to fill in that gap. The earliest fusion occurred at the ilium-ischium-pubis, followed by the acetabular epiphyses. The epiphyses of the innominate and of the femur, tibia, and fibula commence union next at about the same age, except those of the knee 
TABLE 16. Age distribution of stages of union of the proximal tibia (\%)

\begin{tabular}{lcccccccc}
\hline & \multicolumn{4}{c}{$\begin{array}{c}\text { Females } \\
\text { (stage of union) }\end{array}$} & & \multicolumn{3}{c}{$\begin{array}{c}\text { Males } \\
\text { (stage of union) }\end{array}$} \\
\cline { 3 - 5 } \cline { 7 - 9 } Age & $N$ & 1 & 2 & 3 & $N$ & 1 & 2 & 3 \\
\hline 12 & 2 & 100 & - & - & 2 & 100 & - & - \\
13 & 3 & 100 & - & - & 1 & 100 & - & - \\
14 & 2 & 50 & 50 & - & 3 & 100 & - & - \\
15 & 5 & 20 & 80 & - & 3 & 100 & - & - \\
16 & 3 & 33 & 66 & - & 4 & 75 & 25 & - \\
17 & 3 & - & 100 & - & 4 & - & 75 & 25 \\
18 & 5 & - & 20 & 80 & 2 & 50 & - & 50 \\
19 & 4 & - & 50 & 50 & 4 & - & 75 & 25 \\
20 & 4 & - & - & 100 & 6 & - & - & 100 \\
21 & 5 & - & - & 100 & 5 & - & - & 100 \\
\hline
\end{tabular}

TABLE 17. Age distribution of stages of union of the distal tibia (\%)

\begin{tabular}{|c|c|c|c|c|c|c|c|c|}
\hline \multirow[b]{2}{*}{ Age } & \multirow[b]{2}{*}{$N$} & \multicolumn{3}{|c|}{$\begin{array}{c}\text { Females } \\
\text { (stage of union) }\end{array}$} & \multirow[b]{2}{*}{$N$} & \multicolumn{3}{|c|}{$\begin{array}{c}\text { Males } \\
\text { (stage of union) }\end{array}$} \\
\hline & & 1 & 2 & 3 & & 1 & 2 & 3 \\
\hline 12 & 2 & 100 & - & - & 2 & 100 & - & - \\
\hline 13 & 3 & 100 & - & - & 1 & 100 & - & - \\
\hline 14 & 2 & 50 & 50 & - & 3 & 100 & - & - \\
\hline 15 & 5 & 20 & 60 & 20 & 3 & 33 & 66 & - \\
\hline 16 & 3 & 33 & 33 & 33 & 4 & 50 & 25 & 25 \\
\hline 17 & 3 & - & - & 100 & 4 & - & 25 & 75 \\
\hline 18 & 5 & - & - & 100 & 2 & 50 & - & 50 \\
\hline 19 & 4 & - & - & 100 & 4 & - & - & 100 \\
\hline 20 & 4 & - & - & 100 & 6 & - & - & 100 \\
\hline
\end{tabular}

which show a slight delay. Whereas by 19 years the long bones show complete union of epiphyses, this only occurs at age 21-22 in the hipbone. In most epiphyses, females are ahead of males by 1-2 years. Union at the innominate shows considerable overlap between males and females, but in one location females seem to fuse later (ramal epiphysis) and in two other locations at the same time (iliac spine and iliac crest) as males. In all other anatomical locations females are ahead of males. Later fusion of the ramal epiphysis in females maybe related to continued growth of the pubic bone in females, which is the primary factor in producing sexual dimorphism in the pelvic inlet (Coleman, 1969). Although union of the pubis, ilium, and ischium occurs earlier in females, because pelvic growth continues for longer in females, union of later epiphysis occurs at about the same age as males. Because of small sample sizes, individual variability cannot be adequately sampled, thus explaining why in some locations females show a wide range of ages of union and males do not (for example the distal femur).

By establishing the range of variation for epiphyseal fusion in the hipbone and in the lower limb, data in this study can be used to estimate the age of unidentified skeletal remains, either directly or by aiding in the modification of incomplete or imprecise data that have been collected over the years. Only epiphyseal locations at stage 2 (partial union) can be used to establish a lower and upper limit for the probable age at death. If the epiphysis is unfused (Stage 1) or completely fused (Stage 3 , only an upper and lower age limit can be established, respectively. For partially fused epiphyses, when only one location can be assessed, age can be estimated
TABLE 18. Age distribution of stages of union of the proximal fibula (\%)

\begin{tabular}{|c|c|c|c|c|c|c|c|c|}
\hline \multirow[b]{2}{*}{ Age } & \multirow[b]{2}{*}{$N$} & \multicolumn{3}{|c|}{$\begin{array}{c}\text { Females } \\
\text { (stage of union) }\end{array}$} & \multirow[b]{2}{*}{$N$} & \multicolumn{3}{|c|}{$\begin{array}{c}\text { Males } \\
\text { (stage of union) }\end{array}$} \\
\hline & & 1 & 2 & 3 & & 1 & 2 & 3 \\
\hline 12 & 2 & 100 & - & - & 2 & 100 & - & - \\
\hline 13 & 3 & 100 & - & - & 1 & 100 & - & - \\
\hline 14 & 2 & 50 & 50 & - & 3 & 100 & - & - \\
\hline 15 & 4 & 50 & 50 & - & 3 & 100 & - & - \\
\hline 16 & 3 & 66 & 33 & - & 4 & 75 & - & 25 \\
\hline 17 & 3 & - & 33 & 66 & 4 & 25 & 25 & 50 \\
\hline 18 & 4 & - & - & 100 & 2 & 50 & - & 50 \\
\hline 19 & 4 & - & - & 100 & 3 & - & - & 100 \\
\hline 20 & 4 & - & - & 100 & 5 & - & - & 100 \\
\hline
\end{tabular}

TABLE 19. Age distribution of stages of union of the distal fibula (\%)

\begin{tabular}{|c|c|c|c|c|c|c|c|c|}
\hline \multirow[b]{2}{*}{ Age } & \multirow[b]{2}{*}{$N$} & \multicolumn{3}{|c|}{$\begin{array}{c}\text { Females } \\
\text { (stage of union) }\end{array}$} & \multirow[b]{2}{*}{$N$} & \multicolumn{3}{|c|}{$\begin{array}{c}\text { Males } \\
\text { (stage of union) }\end{array}$} \\
\hline & & 1 & 2 & 3 & & 1 & 2 & 3 \\
\hline 12 & 2 & 100 & - & - & 2 & 100 & - & - \\
\hline 13 & 3 & 100 & - & - & 1 & 100 & - & - \\
\hline 14 & 2 & 50 & 50 & - & 3 & 100 & - & - \\
\hline 15 & 5 & 60 & 20 & 20 & 3 & 33 & 66 & - \\
\hline 16 & 3 & 33 & 33 & 33 & 4 & 50 & 50 & - \\
\hline 17 & 3 & - & - & 100 & 4 & - & 25 & 75 \\
\hline 18 & 5 & - & - & 100 & 2 & - & 50 & 50 \\
\hline 19 & 4 & - & - & 100 & 4 & - & - & 100 \\
\hline 20 & 4 & - & - & 100 & 6 & - & - & 100 \\
\hline
\end{tabular}

within a maximum of 6 years for innominate epiphyses and within a maximum of 5 years for long bone epiphysis. These age intervals for maximum error in estimation are obtained by subtracting 1 year to the largest age range of partial union. When more than one location can be examined, in addition to establishing an age range that incorporates information from all epiphyses, a modal age can also be calculated as the most frequent (mode) age where all the locations at Stage 2 overlap. Since adolescent females mature earlier than males, sex should be considered when estimating age from epiphyseal union. If the sex of the remains cannot be determined the age range should be expanded to include the possibility of either sex.

Although sample sizes are small, results in this study are largely comparable with other studies, suggesting that some stages are not necessarily under-represented and not automatically inadequate for age assessments. However, comparisons between studies are sometimes hampered by how different authors report their results. For example, although Stevenson (1924) reported observations on epiphyseal union of dry bone, he did not distinguish between the sexes. One other problem is that interpretations of when epiphyseal union occurs vary and, therefore, studies may give slightly different age estimates for the same event according to the procedure. For example, whereas some authors assert that "the time at which this significant transition between the major stages of absolute non-union and complete union respectively takes place that determines the actual age of union of the epiphysis in question" (Stevenson, 1924: 59 ), other authors refer to fusion as the time at which 
$50 \%$ or more of their sample show complete union (Flecker, 1942). In addition, it is usually not explicit whether the age interval for union corresponds to younger and older ages of partial union or some other criterion. For the purpose of comparison, when authors report ranges for ages of union and do not clarify how they were obtained, it is assumed that they represent the interval between the youngest and oldest ages of partial union.

Few dry bone studies are available in the literature and not all can be directly compared with the results in this study. The samples utilized by McKern and Stewart (1957) and Schaefer and Black (2005) are truncated at age 17 , represent only males and were scored using a slightly different methodology. Given that these studies are inferiorly truncated, only the upper age limits for epiphyseal union can be compared. When the epiphyses of the knee are considered, comparison is hampered by lack of males in Stage 2 of the study sample. The few study sample males at Stage 2 are all younger than the upper age limit of McKern and Stewart (1957) and Schaefer and Black (2005) for epiphyseal union at the knee. In contrast, union at the iliac crest and ischial tuberosity in the study sample is similar to modern Bosnian skeletal material (Schaefer and Black, 2005), but 1-2 years advanced relative to the military sample of McKern and Stewart (1957).

Veschi and Facchini (2002) have also reported the timing of epiphyseal union in several locations in a sample of identified male and female skeletons from Italy, but results are truncated at age 16 . Veschi and Facchini (2002) have also used a three-stage scheme for recording epiphyseal union and their data show a high degree of overlap in ages at Stage 2 of union. However, in Veschi and Facchini's (2002) study, the Stage 2 age range tends to be significantly wider toward the older ages, showing 2-4 years later ages of union. This very wide discrepancy should probably be interpreted as methodological differences in assigning stages of epiphyseal union in dry bone material, possibly related to the expression of the external epiphyseal scar.

Compared with the timing of union of the iliac spine provided by Webb and Suchey (1985) in another dry bone collection, the intervals for union mostly overlap. However, for females, Webb and Suchey (1985) provide a slightly wider age range and, for males, the lower age limit is 2 years younger. These minor differences can probably be ascribed to differences in sample size between this study and Webb and Suchey's (1985) study, which has sampled more variation.

Recently, Coqueugniot and Weaver (2007) have published a comprehensive aging standard for infracranial epiphyseal union based on the Coimbra collection, and using the same scoring methodology. Compared with the data in this study, epiphyseal union in the Coimbra subadults shows a considerable delay. This is particularly true for the latest ages of partial union, where several epiphyses in the Coimbra sample show a delay of 3-4 years (and sometimes 7 years) relative to the Lisbon sample. Similarly, earliest ages of partial union are around 2 years delayed in Coimbra relative to Lisbon. In only 3 out of 14 anatomical locations is epiphyseal union in the Coimbra sample advanced relative to the Lisbon sample, but only for the earliest ages at Stage 2 and never more than 2 years. Coqueugniot and Weaver's (2007) study also shows greater variability in the age of fusion and older ages for both the upper and lower limit of Stages 1 and 3, respectively, again suggesting an overall significant delay. Although the Coimbra collection encompasses slightly early birth cohorts and may represent a lower socioeconomic segment of a predominantly rural population, compared to the Lisbon collection, any differences in socioeconomic or living conditions between the two samples are probably too small to explain the large ossification delay of the Coimbra subadults. In addition, both samples are largely comparable in terms of sample size. Instead, differences in skeletal maturation between the two studies may derive from methodological issues. In the specimens of the Coimbra collection the epiphysis are sometimes glued to the primary ossification centers, therefore, potentially misleading the examiners in the identification of an unfused or partially fused epiphysis. Although Coqueugniot and Weaver (2007) asserted that if they could see any glue, the epiphyseal location was coded as Stage 1 (or "a" in their study), because only two parts which had originally been separated could be glued together, this does not automatically imply that the location was not fused. If an epiphysis, whose union has commenced centrally and has been glued due to postmortem breakage, it will be misclassified if scored as Stage 1. This factor may explain why epiphyseal union seems delayed in the Coimbra collection, together with the possibility of Coqueugniot and Weaver (2007) having assigned later ages of epiphyseal union due to the expression of the external epiphyseal scar. The gluing of epiphysis also raises the question of whether an unfused epiphysis has been misclassified as Stage 2 (partial union), if it has been glued for any unknown reason and no glue and no bony connections between the secondary and primary ossification centers can be observed.

Several radiographic standards have also documented the timing of epiphyseal union at various locations, but data may not be directly comparable with dry bone material. Times of epiphyseal union from radiographic studies and compiled by the Workshop of European Anthropologists (Ferembach et al., 1980) are around 1, 2, or more years later than times of epiphyseal union in the study sample. Since the sources used for this compilation are mostly from the 1950 s, i.e., roughly contemporaneous to the study sample, and mostly representative of normal populations, these differences in timing may derive from methodological differences between radiographic and dry bone observations, namely the late persistence of the radiographic line of epiphyseal union (Krogman and Iscan, 1986). With respect to the radiographic charts of Pfau and Sciulli (1994), they also overlap considerably with the times of the study sample, although some epiphyses show earlier ages of union (females, distal femur), whereas others somewhat later (males, distal tibia). This may be interpreted as a result of small sample sizes in both the study sample and the sample utilized by Pfau and Sciulli (1994) $(n=75)$.

In contrast, timing of epiphyseal union in the charts compiled by Scheuer and Black (2000) almost entirely overlaps the timing of epiphyseal union in the study sample. Only in a few epiphyseal locations does the compilation show slightly younger ages for the lower age limits, particularly for females. Most of the data in this compilation also derive from radiographic studies which predominantly represent the well-off populations (Garn, 1980). Radiographic data reported by Crowder and Austin (2005) also show 1-4 years advancement in timing of union of the distal tibia and fibula in a modern clinical sample, compared to the study sample. However, given 
that commencement of fusion can be detected in radiographs before any union of the epiphyseal line can be visible on dry bone (Krogman and Iscan, 1986), it is not clear whether epiphyseal union in the study sample is delayed relative to Scheuer and Black's (2000) compilation and to Crowder and Austin's (2005) sample, or whether the differences also originate from distinct methodologies. In addition, Crowder and Austin (2005) recorded a stage defined as unclear epiphyseal union, which may suggest some inaccuracy in identifying the lower age limits for initial union. The fact that the open epiphyseal lines can remain visible on dry bone for a considerable time after the radiographs indicate that fusion has commenced (Krogman and Iscan 1986), and other methodological differences may suggest that radiographic standards are better suited to estimate bone age in radiographs and skeletal collections more appropriate to estimate bone age in dry bone material.

The overall pattern seems to be one of the similarities between studies and many of the differences that occur may probably be explained by the study sample being smaller and thus less variability is sampled, by problems of examining restored material (i.e. with glued epiphysis), by the late persistence of the union line in earlier radiographic studies and also differences may be explained by earlier detection of epiphyseal-diaphyseal union in X-rays. If comparisons are done across dry bone or radiographic studies, as to eliminate methodological differences, socioeconomic status will probably explain most of the variation in skeletal maturation between samples. This is true whether socioeconomic differences are measured across temporal (secular trends) or geographical (developed versus developing countries) distances. A small socioeconomic status effect in skeletal maturation at adolescence may explain why the timing of epiphyseal union in the study sample is largely comparable with other similar or well-off samples, even if methodological issues are considered. However, it is likely that important socioeconomic variation may be concealed by sample size, because it limits the amount of variation that can be observed.

Frisancho et al. (1970a,b) report a 5-9\% delay in skeletal maturation at adolescence due to poor nutrition, which in practice represents a delay in epiphyseal union of around 0.75-1.80 years. Similar delays in skeletal maturation have been found by Loder et al. (1993), when applying the Greulich and Pyle (1950) radiographic atlas to contemporaneous children. Therefore, the researcher can probably expect similar maturational delays in populations of lower socioeconomic condition or who have not experienced major improvements in social and economic life (secular trends). On the other hand, given the relative wide age intervals with which age can be established using epiphyseal timing (a maximum of 5-6 years, as mentioned before) a 5-9\% delay in maturation can be a relatively minor error of assessment. The importance of this information relies on the fact that in individuals of lower socioeconomic status, the lower and upper limit for the probable age at death can be shifted upwards (0.75-1.80 years). Although the socioeconomic background of the individual may have less influence in timing of epiphyseal union as once thought, when performing age estimations, forensic anthropologists and bioarchaeologists should still pay special attention to the different levels of modernization or economic development of the population from which the skeletal sample under study is drawn or from which the individual remains being examined originate, as this will improve the accuracy of the age estimate.

\section{CONCLUSIONS}

Data for age at epiphyseal union is particularly useful for the estimation of age at death of adolescent and young adult skeletons. This study provides some guidance in establishing age at death of unidentified skeletal remains and suggests that age in adolescents and young adults can be estimated within 5-6 years using the epiphysis of the innominate, the femur, the tibia, or the fibula. Prior to estimating the age of adolescent and young adult skeletons it is fundamental to estimate the sex because males' epiphyseal union is delayed relative to females' to about 2 years. Although socioeconomic status has a great impact on skeletal maturation, its effects are smaller in adolescence compared with early or late childhood. Despite the small amount of delay in skeletal maturation that can be ascribed to socioeconomic conditions in adolescence, special attention should be paid to the different levels of modernization or economic development of the population from which the remains are likely to derive to establish the most probable age range.

\section{ACKNOWLEDGMENTS}

I thank the three anonymous reviewers for their important contributions to improving the quality of this article. I would also like to acknowledge Prof. Shelley Saunders for assistance throughout my research and the Bocage Museum for institutional support.

\section{LITERATURE CITED}

Acheson RM. 1954. A method of assessing skeletal maturity from radiographs: a report from the Oxford child health survey. J Anat 88:498-508.

Albanese J. 2003. Identified skeletal reference collections and the study of human variation. Ph.D. thesis. Hamilton, McMaster University.

Albert AM, Maples WR. 1995. Stages of epiphyseal union for thoracic and lumbar vertebral centra as a method of age determination for teenage and young adult skeletons. J Forensic Sci 40:623-633.

Banerjee KK, Agarwal BBL. 1998. Estimation of age from epiphyseal union at the wrist and ankle joints in the capital city of India. Forensic Sci Int 98:31-39.

Cardoso HFV. 2005. Patterns of growth and development of the human skeleton and dentition in relation to environmental quality. Ph.D. thesis. Hamilton, McMaster University.

Cardoso HFV. 2006. Brief communication: the collection of identified human skeletons housed at the Bocage Museum (National Museum of Natural History), Lisbon, Portugal. Am J Phys Anthropol 129:173-176.

Cardoso HFV. 2007. Environmental effects on skeletal versus dental development: using a documented subadult skeletal sample to test a basic assumption in human osteological research. Am J Phys Anthropol 132:223-233.

Coleman WH. 1969. Sex differences in the growth of the human bony pelvis. Am J Phys Anthropol 31:125-151.

Coqueugniot H, Weaver TD. 2007. Infracranial maturation in the skeletal collection from Coimbra, Portugal: new aging standards for epiphyseal union. Am J Phys Anthropol. DOI 10.1002/ajpa.20683.

Crowder C, Austin D. 2005. Age ranges of epiphyseal fusion in the distal tibia and fibula of contemporary males and females. J Forensic Sci 50:1001-1007. 
Dreizen S, Spirakis CN, Stone RE. 1967. A comparison of skeletal growth and maturation in undernourished and well-nourished girls before and after puberty. J Pediatr 70:256-263.

Ferembach D, Schwidetzky L, Stloukal M. 1980. Recommendation for age and sex diagnoses of skeletons. J Hum Evol 9: $517-549$.

Flecker H. 1942. Time of appearance and fusion of ossification centers as observed by roentogenographic methods. Am J Roentgenol 47:95-159.

Frisancho AR, Garn SM, Ascoli W. 1970a. Unequal influence of low dietary intakes on skeletal maturation during childhood and adolescence. Am J Clin Nutr 23:1220-1227.

Frisancho AR, Garn SM, Ascoli W. 1970b. Childhood retardation resulting in reduction of adult body size due to lesser adolescent skeletal delay. Am J Phys Anthropol 33:325-336.

Garn SM. 1980. Human growth. Annu Rev Anthropol 9:275292.

Greulich W, Pyle S. 1950. Radiographic atlas of skeletal development of the hand and wrist. Stanford, CA: Stanford University Press.

Himes JH. 1984. An early hand-wrist atlas and its implications for secular change in bone age. Ann Hum Biol 11:71-75.

Hodges PC. 1933. An epiphyseal chart. Am J Roentgenol 30:809-810.

Hoerr NL, Pyle SI, Francis LC. 1962. Radiographic atlas of skeletal development of the foot and ankle: a standard of reference. Springfield, IL: Thomas.

Hunt DR, Albanese, J. 2005. History and demographic composition of the Robert J. Terry Anatomical Collection. Am J Phys Anthropol 127:406-417.

Johnston FE. 1961. Sequence of epiphyseal union in a prehistoric Kentucky population from Indian Knoll. Hum Biol 33:66-81.

Krogman WM, Iscan MY. 1986. The human skeleton in forensic medicine. Springfield, IL: Thomas.

Loder RT, Estle DT, Morrison K, Eggleston D, Fish DN, Greenfield ML, Guire KE. 1993. Applicability of the Greulich and Pyle skeletal age standards to black and white children of today. Am J Dis Child 147:1329-1333.

McKern TW, Stewart TD. 1957. Skeletal changes in young American males. Analyzed from the standpoint of age identification. Environmental Protection Research Division (U.S.
Army Quartermaster Research and Development Command), Technical Report EP-45. Natick, US Army.

Pfau R, Sciulli P. 1994. A method for establishing the age of subadults. J Forensic Sci 39:165-176.

Pickett KE, Haas JD, Murdoch S, Rivera JA, Martorell R. 1995. Early nutritional supplementation and skeletal maturation in Guatemalan adolescents. J Nutr 125 (Suppl 4):1097S-1103S.

Pyle SI, Hoerr NL. 1955. A radiographic standard of reference for the growing knee. Springfield, IL: Thomas.

Schaefer MC, Black SM. 2005. Comparison of ages of epiphyseal union in North American and Bosnian skeletal material. J Forensic Sci 50:777-784.

Scheuer L, Black S. 2000. Developmental juvenile osteology. London: Academic.

Schmeling A, Reisinger W, Loreck D, Vendura K, Markus W, Geserick G. 2000. Effects of ethnicity on skeletal maturationconsequences for forensic age estimations. Int J Legal Med 113:253-258

Schmeling A, Schulz R, Danner B, Rosing FW. 2006. The impact of economic progress and modernization in medicine on the ossification of hand and wrist. Int J Legal Med 120:121-126.

Stevenson PH. 1924. Age order of epiphyseal union in man. Am J Phys Anthropol 7:53-92.

Tanner JM, Whitehouse RH, Cameron N, Marshall WA, Healy MJR, Goldstein H. 1983. Assessment of skeletal maturity and prediction of adult height (TW2 method). New York: Academic.

Todd TW. 1931. Differential skeletal maturation in relation to sex, race, variability and disease. Child Dev 2:49-65.

Ubelaker DH. 1987. Estimating age at death from immature human skeletons: an overview. J Forensic Sci 32:1254-1263.

Ubelaker DH. 2005. Estimating age at death. In: Rich J, Dean DE, Powers RH, editors. Forensic medicine of the lower extremity: human identification and trauma analysis of the thigh, leg, and foot. Totowa: Humana. p 99-112.

Veschi S, Facchini F. 2002. Recherches sur la collection d'enfants et d'adolescents d'âge et de sexe connus de Bologne (Italie): diagnose de l'âge sur la base du degré de maturation osseuse. Bull Mem Soc Anthropol Paris 14:263-294.

Webb PA, Suchey JM. 1985. Epiphyseal union of the anterior iliac crest and medial clavicle in a modern multiracial sample of American males and females. Am J Phys Anthropol 68: 457-466. 